\title{
A polycrystal based numerical investigation on the temperature dependence of slip resistance and texture evolution in magnesium alloy AZ31B
}

\author{
Yao Liu, Yujie Wei* \\ LNM, Institute of Mechanics, Chinese Academy of Sciences, Beijing 100190, PR China
}

\section{A R T I C L E I N F O}

\section{Article history:}

Received 4 June 2013

Received in final revised form 27 August

2013

Available online 9 October 2013

\section{Keywords:}

Hexagonal-close-packed magnesium

Polycrystal plasticity-B

Deformation twinning-A

Texture evolution

Critical resolved shear stress (CRSS)

\begin{abstract}
A B S T R A C T
Low thermoplastic formability is a key factor limiting the usage of magnesium alloys, which otherwise can have broad application in automotive industry for their competitive strength to density ratio. Combining with experimental calibration and validation, we report a systematic numerical investigation about the plastic deformation of magnesium alloy AZ31B at different temperatures and subjected to different boundary conditions. By employing 3D Voronoi grains based microstructure and the crystal plasticity constitutive model developed by Staroselsky and Anand (2003), which accounts for both dislocation slip and deformation twinning in polycrystalline magnesium, we estimate the dependence of critical resolved shear stresses (CRSS) of different slip/twinning systems on temperature. We further obtain the fractional plastic strains contributed by individual slip/twinning systems at different loading conditions. Grain level deformation analysis indicates that there exists significant stress and plasticity inhomogeneity among grains.
\end{abstract}

(c) 2013 Elsevier Ltd. All rights reserved.

\section{Introduction}

The application of magnesium alloys in automotive industry as alternatives to currently used steel- and aluminum-based automobile parts has gained increasing interests in the last decade for their competitive strength to density ratio and being more environmental friendly (Alves et al., 2001; Haferkamp et al., 2001; Kulekci, 2008; Liu et al., 2012; Luo, 2002; Wei and Anand, 2007). Unlike their counterparts, however, magnesium alloys are notorious for poor thermoplastic formability, a key factor limiting their wider application (Kim et al., 2008; Lee et al., 2008b). The poor formability in magnesium originates from its hexagonal-close-packed (HCP) crystallographic nature. In contrast to face-centred-cubic (FCC) metals where all 12 slips systems for dislocation motion have roughly equal resistance and hence it is easy to find five independent slip systems - the Taylor's minimum shear principle to be fulfilled for compatible plastic deformation (Leffers, 2001; Styczynski et al., 2004; Taylor, 1938), plastic deformation mechanisms in HCP crystalline magnesium are rather complex. Plasticity in magnesium may involve more than five kinds of slip/twinning systems (Styczynski et al., 2004; Taylor, 1938): the basal $\langle a\rangle$ slip, the non-basal $\langle a\rangle$ slip, the non-basal $\langle c+a\rangle$ slip, the extension $\operatorname{twin}\{01 \overline{1} 2\}\langle 0 \overline{1} 11\rangle$, and the contraction twin $\{0 \overline{1} 11\}$ $\langle 0 \overline{1} 1 \overline{2}\rangle$. At room temperature, the slip resistance to basal $\langle a\rangle$ dislocation slip is much lower than other slip/twinning systems but the basal $\langle a\rangle$ slip systems alone cannot supply arbitrary compatible deformation required by the Taylor principle. Activation of non-basal slip and/or twinning systems is hence necessary (Agnew and Duygulu, 2005; Koike et al., 2003a). As a result, the collective mechanical response induced by the activation of heterogeneous slip systems show distinct features in contrast to its FCC counterparts (Choi et al., 2010; Hama and Takuda, 2011) due to the strong anisotropy (Gottstein, 2004).

\footnotetext{
* Corresponding author.

E-mail address: yujie_wei@Inm.imech.ac.cn (Y. Wei).
} 
Given the strong correlation between plasticity in magnesium and its formability, many research groups have carried out experiments and theoretical analysis to explain and predict the deformation mechanisms of magnesium subjected to various boundary value problems (Agnew et al., 2006; Beyerlein et al., 2011; Choi et al., 2010; Cipoletti et al., 2011; Fernandez et al., 2011; Khan et al., 2006; Lévesque et al., 2010; Lee et al., 2008a; Li et al., 2010; Mayama et al., 2011; Proust et al., 2009; Staroselsky and Anand, 2003; Walde and Riedel, 2007a; Wang et al., 2010a). Theoretically, crystal plastic model has been proved to be an effective way to capture the activation of different plastic deformation mechanisms at the microscopic level. There exist several pioneering works and subsequent developments. For example, Staroselsky and Anand (2003) put forward a constitutive model considering deformation by both slip and twinning and implemented it into a finite-element program to simulate the stress-strain response and texture evolution of AZ31B. The model stemmed from the crystal plasticity model for plastic deformation of FCC materials by slip and twinning (Kalidindi, 1998; Myagchilov and Dawson, 1999; Staroselsky and Anand, 1998). In those models, deformation twinning is regarded as pseudo slip, a strategy originally suggested by Van Houtte (1978) and Tomé et al. (1991). Soon several versions of crystal plasticity model for HCP metals emerged, with new features to enrich the physics of modeling. For example, Fernandez et al. considered cross-hardening between slip and twinning systems based on the constitutive model (Fernandez et al., 2011); a rate-sensitive crystal plasticity constitute model was also used by Lévesque et al. (2010) to simulate the deformation in magnesium alloy AM30; Walde and Riedel used a viscoplastic self-consistent model to simulate the forming processes of a variety of materials where deformation twinning cannot be avoided (Walde and Riedel, 2007b); Li et al. proposed a TWINLAW based on three phenomenological deformation modes (slip, twinning and de-twinning) (Li et al., 2010); Beyerlein et al. developed a crystal plasticity constitutive model dealing with the nucleation of deformation twins (Beyerlein et al., 2011); Wang et al. developed a large strain elastic-viscoplastic self-consistent model for polycrystalline materials and employed it into AZ31B sheet (Wang et al., 2010a,b); Kochmann and Le presented an energy-based micromechanical model and described the mechanical characteristics of deformation twinning (Kochmann and Le, 2009); and Mu et al. used a modified grain interaction model to simulate the texture evolution of AZ31 at different temperatures (from 473 to $673 \mathrm{~K}$ ) based on twin reorientation scheme of Tomé and the cluster type Taylor models (Mu et al., 2010, 2011).

While substantial progress has been achieved for understanding the plasticity in magnesium alloys, there are few theoretical works devoted to the plastic deformation mechanism in magnesium at temperatures between 78 and $473 \mathrm{~K}$, a temperature range changing magnesium alloy AZ31B from brittle to ductile. Experimentally, the temperature dependence of the critical resolved shear stress (CRSS) for basal $\langle\mathbf{a}\rangle$ slips (Graff et al., 2007), prism 〈a $\rangle$ slip (Cazacu et al., 2006; Lee et al., 2008a), and second-order pyramidal $\langle\mathrm{c}+\mathrm{a}\rangle$ slips (Agnew and Duygulu, 2005; Lee et al., 2009; Lévesque et al., 2010) have been explored. It is interesting to see that in contrast to the other two groups, Ando and Tonda (2000) reported larger CRSS in second-order pyramidal $\langle c+a\rangle$ slips at higher temperatures. Since the second-order pyramidal slips are capable of producing deformation along the $c$-axis in single crystalline magnesium, it may be crucial for ductility enhancement if such slips can be activated, as alternatives to deformation twinning. It is hence desired to have a systematical understanding on the competition between the aforementioned slips and deformation twinning at different temperatures and at the grain level, and to reveal the correlation between deformation mechanisms with strain hardening observed in the stress-strain response of magnesium alloys. In addition, previous simulations are largely based on equal weighted elements to represent individual grains. Deformation compatibility induced by grain structures and its consequent influence on mechanical properties cannot be accounted in that circumstance. In this research, we have performed experiments for an initially-textured magnesium alloy AZ31B deforming by crystallographic slip and twinning at different temperatures, and applied the crystal plasticity based constitutive modeling (Staroselsky and Anand, 2003) to capture the deformation behavior of AZ31B at several temperatures and subjected to different loading paths. With the experimental validation of the model, we reveal (a) the dependence of slip/twinning resistance on temperature, (b) the contribution of individual deformation mechanisms at different temperature, and (c) the correlation between strain hardening and texture evolution at different temperatures.

\section{Experimental observation}

\subsection{Sample preparation and initial structures}

As-drawn AZ31B (96.486\%Mg, 2.798\%Al, 0.715\%Zn, Balanced Mn, Fe in wt.\%) rods was bought from the Good Fellow Inc. As for the mechanical properties of AZ31B, both initial crystal orientations (Gottstein, 2004; Wang et al., 2012; Yang et al., 2004; Yuan et al., 2011) and grain size (Barnett et al., 2004; Kim, 2009; Mabuchi et al., 2003; Mo et al., 2011; Wei and Anand, 2007) are of great impact. We give the information about sample preparation, initial microstructure, and initial texture in Fig. 1. Cylindrical rods with length of $12 \mathrm{~mm}$ and diameter of $6 \mathrm{~mm}$ were cut from AZ31B rods for quasi-static uniaxial compression at different temperatures. $L$ - and $R$-samples indicate that applied loading will be parallel to the $L$ direction and the $R$ direction, respectively, as illustrated in Fig. 1a. Along the $L$ direction, standard dog bone samples were prepared for quasistatic uniaxial tension test, while in the $R$ direction, samples with gauge length about $4 \mathrm{~mm}$ and diameter of $3 \mathrm{~mm}$ are used. All tests were carried out at the strain rate of $1 \times 10^{-3} / \mathrm{s}$. Low temperature $(78 \mathrm{~K})$ tests were performed while immersing the samples in liquid nitrogen. We use temperature chamber for tests at $473 \mathrm{~K}$. 


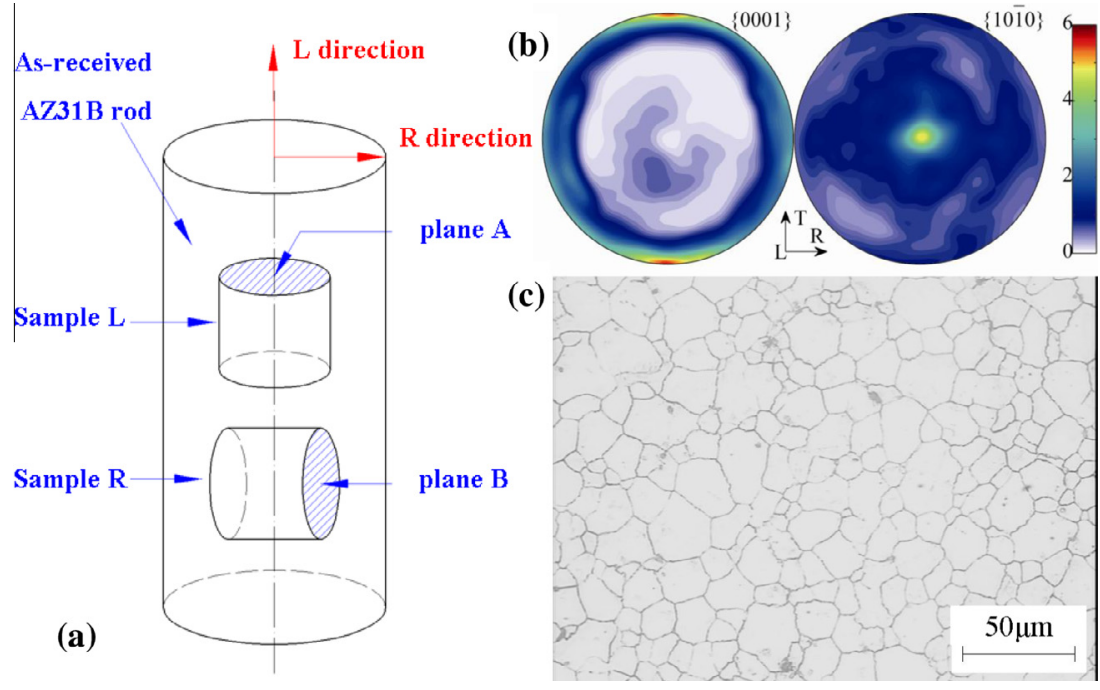

Fig. 1. Sample preparation and initial structures. (a) Illustration for the characteristic directions and the XRD reflecting planes. In what follows, we use $L / R$ samples to refer samples loading along the $L / R$ direction. (b) Initial pole figures from experiments. (c) Optical micrograph of as-received AZ31B rod in plane A.

Pole figures of the initial and deformed samples were obtained by using Siemens D5000 diffractometer with copper-K radiation. Original pole figure data from X-ray diffraction (XRD) were corrected for background and defocusing. We then use the MTEX package in Matlab (Bachmann et al., 2010; Hielscher and Schaeben, 2008) to abstract the orientation distribution function (ODF). To ensure the reliability of the way for texture measurement, we conduct two independent XRD measurements (one from plane A, and the other from plane B) and find no difference between those two measurements. We show in Fig. 1b the experimental pole figures of the initial sample obtained from plane A. We can see from the initial pole figures on $\{0001\}$ and $\{10 \overline{1} 0\}$ crystallographic planes that there exist strong texture in as-drawn AZ31B, and a large proportion of $\{10 \overline{1} 0\}$ prismatic planes are parallel to the axial direction of the as-drawn AZ31B rods, which is consistent with previous reports (Eros and Smith, 1961; Gottstein, 2004). For microstructure examination, the surface of an undeformed sample was etched in $100 \mathrm{ml}$ ethanol, $5 \mathrm{~g}$ picric acid and $10 \mathrm{ml}$ acetic acid solution for $20 \mathrm{~s}$. Fig. 1c shows the optical micrograph of as received AZ31B rod in plane A, and the average grain size is about $16 \mu \mathrm{m}$.

\subsection{Stress-strain curves and mechanical properties of $A Z 31 B$}

We show in Fig. 2 the stress-strain behavior of AZ31B at different temperatures; the end of each curve indicates corresponding failure point. For each type of curve, we test more than two independent samples, and find the stress-strain behavior highly repeatable. We summarize typical mechanical properties of AZ31B in Table 1. As temperature increases, the failure

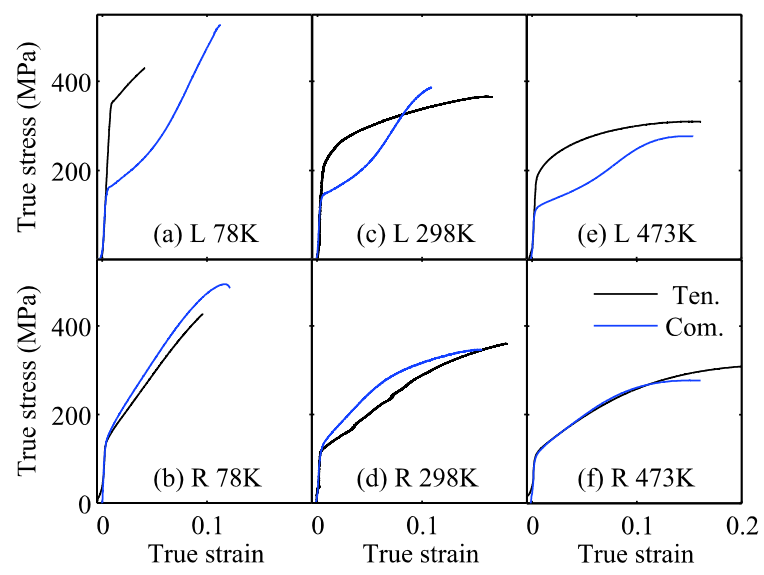

Fig. 2. True stress versus true strain for AZ31B at different temperatures: (a) The $L$-sample at $78 \mathrm{~K}$. (b) The $R$-sample at $78 \mathrm{~K}$. (c) The $L$-sample at $298 \mathrm{~K}$. (d) The $R$-sample at $298 \mathrm{~K}$. (e) The $L$-sample at $473 \mathrm{~K}$. (f) The $R$-sample at $473 \mathrm{~K}$. 
Table 1

Summarized mechanical properties of AZ31B subjected to both tensile (' $T$ ) and compressive (' $C$ ) deformation along different directions and at different temperatures.

\begin{tabular}{|c|c|c|c|c|c|c|c|c|c|c|c|c|}
\hline \multirow{3}{*}{$\begin{array}{l}\text { Samples } \\
\text { Temperature/K } \\
\text { Modes }\end{array}$} & \multicolumn{6}{|c|}{$L$-sample } & \multicolumn{6}{|c|}{$R$-sample } \\
\hline & \multicolumn{2}{|l|}{78} & \multicolumn{2}{|l|}{298} & \multicolumn{2}{|l|}{473} & \multicolumn{2}{|l|}{78} & \multicolumn{2}{|l|}{298} & \multicolumn{2}{|l|}{473} \\
\hline & $T$ & $C$ & $T$ & $C$ & $T$ & C & $T$ & C & $T$ & C & $T$ & $C$ \\
\hline $0.2 \% \sigma_{y} / \mathrm{MPa}$ & 352 & 161 & 206 & 142 & 192 & 120 & 164 & 150 & 115 & 121 & 108 & 109 \\
\hline$\sigma_{u t s} / \mathrm{MPa}$ & 417 & 607 & 314 & 437 & 275 & 324 & 395 & 550 & 298 & 406 & 250 & 344 \\
\hline$\varepsilon_{f} \mid \%$ & 4 & 11 & 21 & 11 & 29 & 39 & 10 & 11 & 21 & 16 & 36 & 37 \\
\hline
\end{tabular}

strain increases but the ultimate tensile strength decreases. Strong anisotropy in stress-strain behavior for $L$-samples is observed. The ratios of $0.2 \%$ tensile yielding strength $\sigma_{y}^{(\mathrm{T})}$ over that under compression $\sigma_{y}^{(\mathrm{C})}$ are $2.19,1.45$ and 1.60 , in turn, at 78 , 298 and $473 \mathrm{~K}$; while in $R$-samples, strength asymmetry is relatively weak.

We note that the strong stress-strain asymmetry seen in Fig. 2 has been broadly observed in magnesium alloys. It is one of the critical restrictions for their applications as structural materials (Graff et al., 2007; Yang and Ghosh, 2006). Agnew and Duygulu (2005) suggested that the initial texture and the non-basal cross-slip of dislocations could be the major cause of the stress-strain asymmetry; Chino et al. (2008) found that deformation twinning may play a role; Grain boundary sliding is also proposed as a possibility (Barnett et al., 2009), and reducing grain size is found to alleviate the yielding asymmetry significantly (Wei and Anand, 2007; Yang and Ghosh, 2006). With the information given in Fig. 2, we find out that the texture of initial sample along the loading direction has a fundamental influence on the stress-strain curve of AZ31B. The grain boundary and grain size effect can be ruled out here given both $L$ - and $R$-samples are cut from the same as-drawn AZ31B bar.

\section{3. fracture surface $\mathcal{E}$ microstructure}

To shed light on the causes for failure, we performed fractographic examination. Fig. 3 shows both the macroscopic patterns and fracture surfaces of $L$-samples after tension. Fracture modes vary greatly in samples deforming at different temperatures. For AZ31B subjected to tension at $78 \mathrm{~K}$ (Fig. 3a), it fails in mode I type fracture with very limited amount of plasticity (no more than $4 \%$ ). While in compression, the sample sustained a total strain about $11 \%$ and failed in shear mode

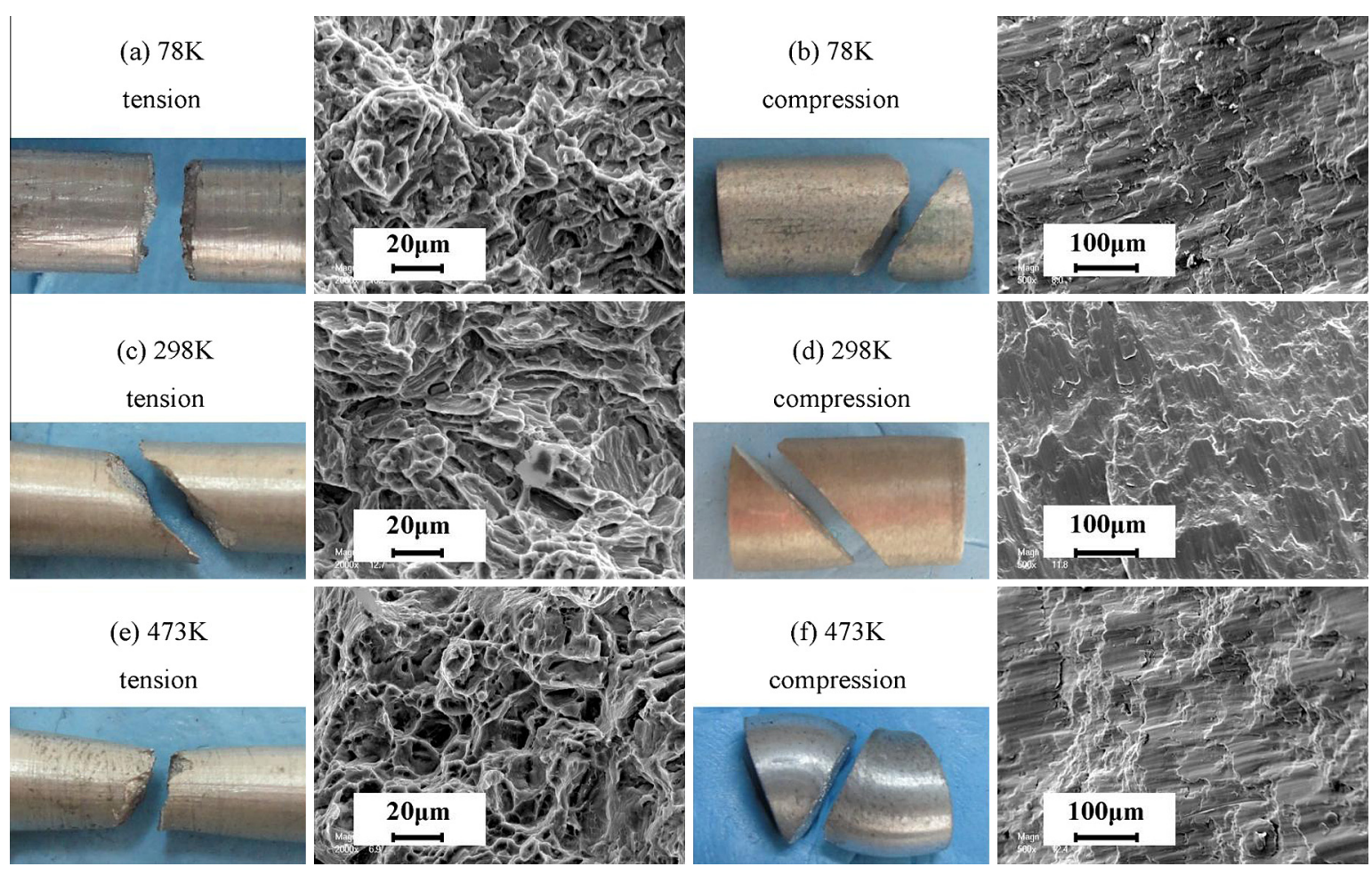

Fig. 3. Macroscopic fracture patterns and the fracture surfaces of samples deforming at different temperatures. Results from tension (a) and compression (b) at $78 \mathrm{~K}$. Results from tension (c) and compression (d) at $298 \mathrm{~K}$. Results from tension (e) and compression (f) at $473 \mathrm{~K}$. 
(Fig. 3b). Corresponding fractography in the tensile sample shows many stacks of layers in dimples with typical sizes close to the grain size, implying the cleavage across basal planes as well as intergranular failure. In compression, there are large areas of shining flat planar structures, most likely left by shearing in basal planes. In contrast, shear fracture is observed when deforming at $298 \mathrm{~K}$ and for both tension and compression (Fig. 3c and d). Cleavage fracturing is now the dominant mechanism for tensile failure, as evidently shown by the stacking of tablets (Fig. 3c). While deforming at $473 \mathrm{~K}$, the fractography still show the trend of shearing in basal planes under compression (Fig. 3f); under tension, coalescence of micro voids which are much smaller than typical grain sizes seems to be the primary reason for the macroscopic diffusive localization (Fig. 3e).

Therefore, as temperature increases, the tensile failure modes transit from intragranular failure to cleavage failure, and to micro void coalescence. Plastic deformation in grain interiors transits from twinning dominated plasticity to the combination of dislocation slip and deformation twinning. By further checking the macroscopic shape change, we find that for $R$-samples subjected to quasi-static compression at $298 \mathrm{~K}$, the original circular cross-section evolves to be elliptical with an eccentricity about 0.43 (Fig. 8a), and such phenomenon is not seen in $L$-samples. We shall get back to this problem with crystal plasticity simulations.

\section{The crystal plasticity model for slip and deformation twinning}

With the detailed deformation behavior observed from experiments, we employ the classical framework of single-crystal plasticity theory (Ma et al., 2012) to model deformation twinning in the continuum mechanics frame, in order to reveal the correlations between experimental observations and active plastic deformation mechanisms. The theoretical scheme developed by Staroselsky and Anand $(1998,2003)$ is adopted. We used the user material subroutine for Abaqus developed by Staroselsky and Anand (1998). We further enrich the constitutive theory and the user subroutine by including self-hardening mechanisms. For completeness, we repeat here part of the key ingredients. In such a framework, the deformation gradient $\boldsymbol{F}$ at a material point is decomposed into elastic $\left(\boldsymbol{F}^{e}\right)$ and plastic $\left(\boldsymbol{F}^{p}\right)$ parts as

$$
\boldsymbol{F}=\boldsymbol{F}^{e} \boldsymbol{F}^{p},
$$

with $\operatorname{det}\left(\boldsymbol{F}^{e}\right)>0$ and $\operatorname{det}\left(\boldsymbol{F}^{p}\right)=1$. Plastic flow takes place through both dislocation slip and deformation twinning in prescribed crystallographic slip/twinning systems. Here, we label dislocation slip systems by $i$ and twin systems by $\alpha$. At the initial configuration, each slip system is defined by a slip/twinning direction $\boldsymbol{m}_{0}$ and a slip/twinning-plane normal $\boldsymbol{n}_{0}$. The Green elastic strain measure $\boldsymbol{E}^{e}$ and the symmetric second Piola-Kirchhoff stress tensor $\boldsymbol{T}$ are hence defined respectively as

$$
\boldsymbol{E}^{e} \equiv(1 / 2)\left(\boldsymbol{F}^{e T} \boldsymbol{F}^{e}-1\right) \text { and } \boldsymbol{T} \equiv \boldsymbol{C E}^{e},
$$

where the superscript ' $T$ ' stands for the transpose of a tensor and $\boldsymbol{C}$ is the fourth order tensor of elastic moduli. The resolved shear stress $\tau$ on a slip/twinning system $\left(\boldsymbol{m}_{0}, \boldsymbol{n}_{0}\right)$ is calculated as

$$
\tau=\left(\boldsymbol{F}^{e T} \boldsymbol{F}^{e} \boldsymbol{T}\right) \cdot\left(\boldsymbol{m}_{0} \otimes \boldsymbol{n}_{0}\right)
$$

The evolution of the plastic deformation gradient, on multiple $i$-th/ $\alpha$-th slip/twin systems, is given as

$$
\boldsymbol{F}^{p}(\tau)=\left\{1+\sum_{i} \Delta \gamma^{i} \boldsymbol{S}_{0}^{i}+\sum_{\alpha} \Delta \gamma^{\alpha} \boldsymbol{S}_{0}^{\alpha}\right\} \boldsymbol{F}^{p}(t), \quad \boldsymbol{S}_{0}^{i} \equiv \boldsymbol{m}_{0}^{i} \otimes \boldsymbol{n}_{0}^{i} \text { and } \boldsymbol{S}_{0}^{\alpha} \equiv \boldsymbol{m}_{0}^{\alpha} \otimes \boldsymbol{n}_{0}^{\alpha}
$$

where $\boldsymbol{S}_{0}^{i}$ and $\boldsymbol{S}_{0}^{\alpha}$ are the Schmid tensor for the $i$-th slip system and the $\alpha$-th twinning system, respectively. We determine the incremental shear $\Delta \gamma$ due to slip/twinning by using the consistency condition in the rate-independent plasticity scheme, with known resolved shear stress $\tau$ and resistance $S^{i} / S^{\alpha}$ on the slip/twinning systems.
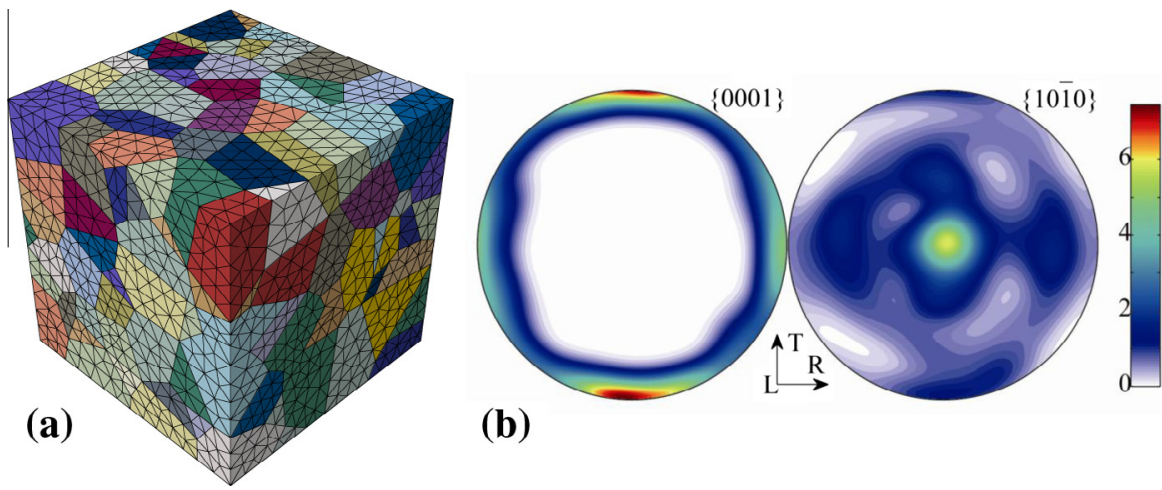

(b)

Fig. 4. Initial microstructures and texture used for simulations. (a) The microstructure for simulations, containing 300 grains. (b) The initial pole figures for simulations (based on measurements shown in Fig. 1c). A total of 300 weighted crystal orientations are used. 

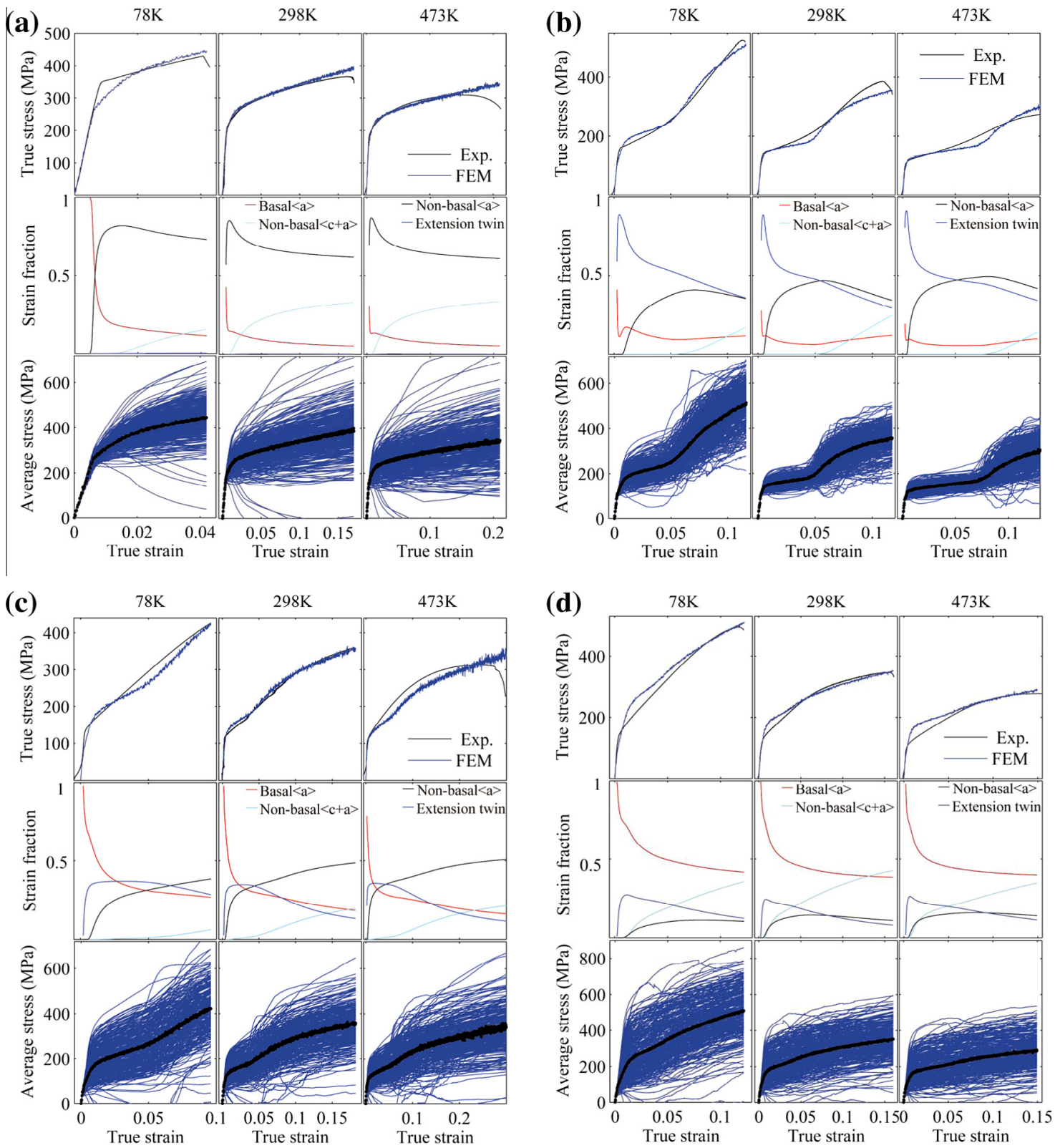

Fig. 5. Mechanical behavior of polycrystals from simulations. The comparison of stress-strain curves between simulations and experiments, strain fraction curves, and averaged stress of each grain for samples deforming at different temperatures, are shown. (a) L-sample in tension, stress-strain responses at different temperatures (top); strain fraction as a function of strain (middle); and average principal stress in each grain (middle). Averaged true stress of the model is shown in black. (b) $L$-sample in compression. (c) $R$-sample in tension. (d) $R$-sample in compression.

We adopt a simple phenomenological model for the evolution of $S^{i}$ and $S^{\alpha}$ (Kalidindi et al., 1992):

$$
S^{i}(\tau)=S^{i}(t)+\sum_{j} h_{s l}^{i j}(t) \Delta \gamma_{s l}^{j}, \text { where } h_{s l}^{i j}=q_{s l}^{i j} h_{s l}^{j}
$$

Here $h_{s l}^{i j}$ are components of the hardening matrix, and

$$
q_{s l}^{i j}=\left[q_{s l}+\left(1-q_{s l}\right) \delta^{i j}\right]
$$

is the matrix describing latent hardening, with $q_{s l}=1.0$ for co-planar systems and $q_{s l}=1.4$ for non-coplanar systems, and

$$
h_{s l}^{j}=h_{s l, 0}\left(1-\frac{S_{s l}^{j}}{S_{s l}}\right)^{a_{s l}}
$$



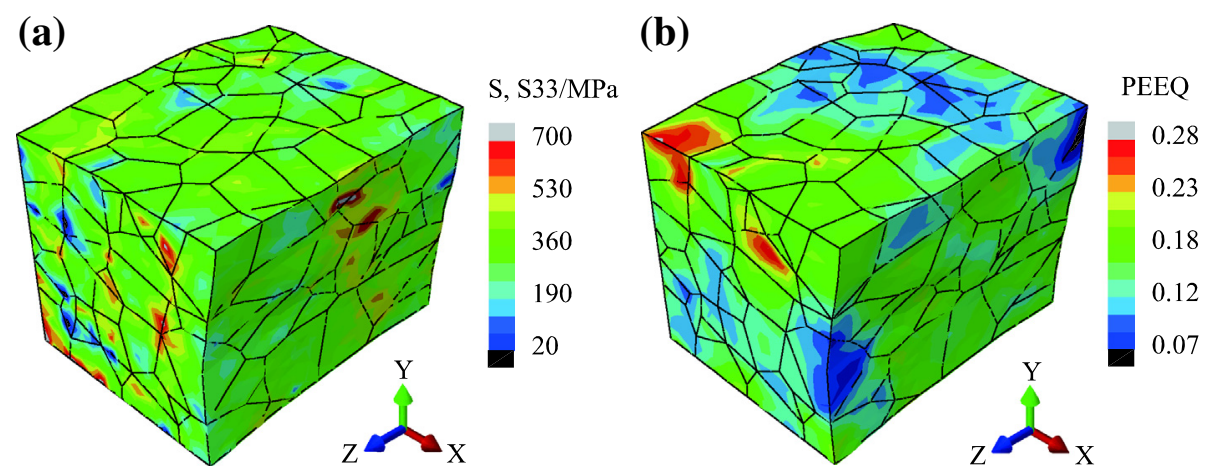

Fig. 6. Deformation in the $L$-sample under tension at $298 \mathrm{~K}$ from simulations. Different types of contours at the strain of 0.17 : (a) maximum principal stress, (b) the equivalent plastic strain.
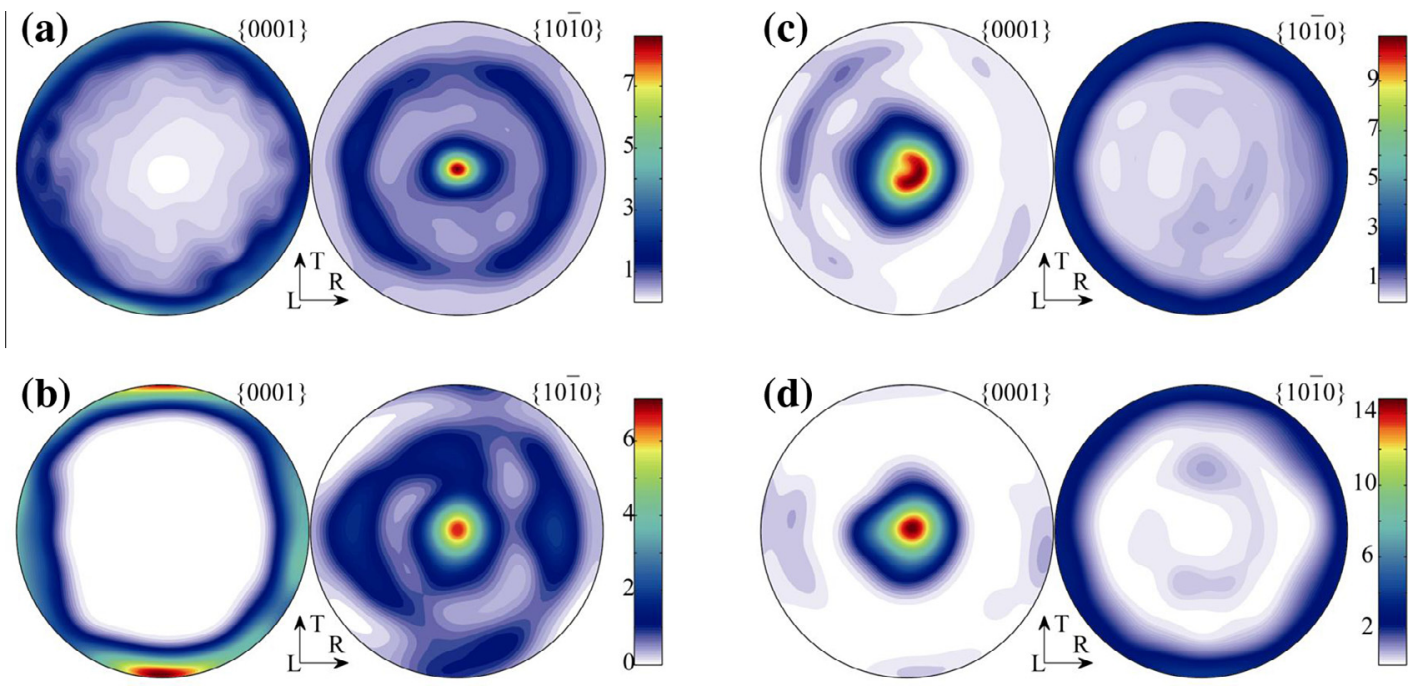

Fig. 7. The pole figures for $L$-sample after deformation at $298 \mathrm{~K}$ : (a) Experimental results at 0.17 tensile strain. (b) Simulated results at 0.17 tensile strain. (c) Experimental results at 0.12 compressive strain. (d) Simulated results at 0.12 compressive strain.
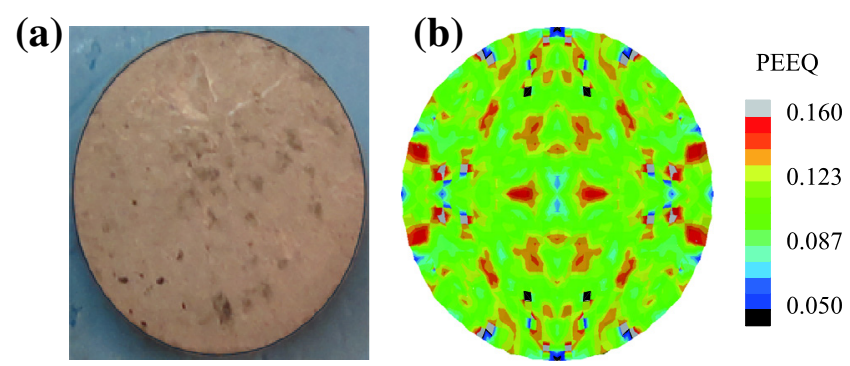

Fig. 8. Macroscopic shape change in $R$-samples under compression. (a) Elliptical cross-section for $R$-sample after 0.17 compressive strain at room temperature. (b) The corresponding simulated result. The eccentricity from experiment is 0.43 and that from simulation is 0.35 .

is the single slip hardening rate. So we have $\left\{h_{s l .0}, S_{s l}, a_{s l}\right\}$ as hardening parameters for dislocation slip, which are taken to be identical for each type of slip systems. The twin system deformation resistances are taken to evolve in the form:

$$
S^{\alpha}(\tau)=S^{\alpha}(t)+\sum_{j} h_{t w}^{\alpha j}(t) \Delta \gamma_{t w}^{j}, \text { where } h_{t w}^{\alpha j}=q_{t w}^{\alpha j} h_{t w}^{j}
$$

Similarly, $h_{t w}^{\alpha j}$ are components of the hardening matrix by deformation twinning, and 


$$
q_{t w}^{\alpha j}=\left[q_{t w}+\left(1-q_{t w}\right) \delta^{\alpha j}\right]
$$

is the latent hardening matrix, with $q_{t w}=1.0$ for co-planar systems and $q_{t w}=1.4$ for non-coplanar systems. It is noted that the expression for latent hardening is taken from that used for FCC materials (Li et al., 2012; Ma et al., 2012). Its applicability to HCP materials remains to be an open question and calls for further experimental work. For the single twinning hardening rate,

$$
h_{t w}^{j}=h_{t w, 0}\left(1-\frac{S_{t w}^{j}}{S_{t w}}\right)^{a_{t w}}
$$

The three $\left\{h_{t w, 0}, S_{t w}, a_{t w}\right\}$ hardening parameters are taken to be identical for the same type of twinning systems. We note that cross-hardening between slip systems and twinning is not considered here given our limited knowledge on this aspect at this moment.

Twinning is considered as pseudo-slip. Different to dislocation slip, however, deformation twinning will result in the rotation of the lattice in the region of the crystal that has gone through twinning (Kelly and Knowles, 2012; Pitteri, 1985, 1986). For magnesium alloys AZ31B, we consider the twin elements $\left\{\boldsymbol{K}_{1}, \boldsymbol{K}_{2}, \boldsymbol{\eta}_{1}, \boldsymbol{\eta}_{2}\right\}$ defined by

$$
\boldsymbol{K}_{1}=\{10 \overline{1} 2\}, \quad \boldsymbol{K}_{2}=\{\overline{1012}\}, \quad \boldsymbol{\eta}_{1}=\langle\overline{1} 011\rangle, \quad \boldsymbol{\eta}_{2}=\langle\overline{101} \overline{1}\rangle .
$$

With the definition of $\boldsymbol{p}$ being a unit vector in the $\boldsymbol{\eta}_{1}=\langle\overline{1011}\rangle$ direction, and $q$ being the unit vector normal to the $\boldsymbol{K}_{1}=\{10 \overline{1} 2\}$ plane, the rotations which carry the matrix lattice to twinned lattice and the inverse (or de-twinning) are given by, respectively,

$$
\boldsymbol{R}^{t w}=2 \boldsymbol{q} \otimes \boldsymbol{q}-1 \text { and } \boldsymbol{R}^{d w}=2 \boldsymbol{p} \otimes \boldsymbol{p}-1 .
$$

That is, if $\boldsymbol{x}_{a}$ are the lattice vectors of the matrix crystal, then the lattice vectors in the twinned region are given by $\boldsymbol{e}_{a}=\boldsymbol{R}^{t w} \boldsymbol{x}_{a}$. As long as the accumulative pseudo-slip in a twinning system reaches to a threshold $\lambda$, we will rotate the matrix lattice to the twinned lattice in each single crystal. For further details the reader is referred to (Staroselsky and Anand, 1998, 2003).

\section{Numerical modeling on deformation mechanisms in AZ31B}

\subsection{Material parameters for $A Z 31 B$}

Now we use the adopted constitutive model to simulate the mechanical deformation of AZ31B at different temperatures. Simulation procedure was conducted using the finite element program ABAQUS/Explict with the user material subroutine. To represent crystalline structures, we generate a polycrystalline structure containing 300 voronoi grains, with each one representing a single crystal (see Fig. 4a). Each grain is meshed into C3D4 elements. Detailed material parameters are given below.

- Elastic properties: The elastic constants for magnesium at different temperatures are chosen to be: $C_{11}=58 \mathrm{GPa}$, $C_{12}=25 \mathrm{GPa}, C_{13}=20.8 \mathrm{GPa}, C_{33}=61.2 \mathrm{GPa}, C_{55}=16.6 \mathrm{GPa}$ (Eros and Smiths, 1961; Hearmon, 1946; Simmons and Wang, 1971; Staroselsky and Anand, 2003). We ignore the rather weak dependence of the elastic constants on temperature.

- Initial texture: The experimentally measured orientation data for the as-drawn AZ31B rods (Fig. 1b) are discretized by 300 weighted orientations (as seen in Fig. 4b) based on the volume of each voronoi grain.

- Slip/twinning systems and initial slip/twinning resistances: The easy crystallographic slip in HCP single crystals are $\langle a\rangle$ closed-packed directions, and $\langle c+a\rangle$ slip/twinning directions to accommodate straining in the $c$-axis. Since contraction twinning takes a little fraction in the deformed samples (Barnett, 2007; Ma et al., 2012; Wu et al., 2012), we choose four representative slip/twinning systems in our simulation: the three $\{0001\}\langle 11 \overline{2} 0\rangle$ slips, the six $\{10 \overline{1} 1\}\langle\overline{1} 2 \overline{1} 0\rangle$ slips, the $\operatorname{six}\{11 \overline{2} 2\}\langle\overline{1} 1 \overline{1} 23\rangle$ slips, and the six $\{10 \overline{1} 2\}\langle\overline{1} 011\rangle$ extension twin. The initial resistances are shown in Table 2 . These values are temperature dependent and are usually higher at lower temperatures. We shall explore their detailed temperature dependence via the combination of experiments and numerical investigations. It is worth noting that we have used

Table 2

\begin{tabular}{|c|c|c|c|c|c|c|c|}
\hline \multirow[t]{2}{*}{$\mathrm{K}$} & \multicolumn{4}{|c|}{ Slip resistance/MPa } & \multicolumn{3}{|c|}{ Hardening/MPa } \\
\hline & $S_{\text {basal }\langle a\rangle \text { slip }}$ & $S_{\text {non-basal }\langle\text { a }\rangle \text { slip }}$ & $S_{\text {non-basal }\langle\mathrm{c}+\mathrm{a}\rangle \text { slip }}$ & $S_{\text {T-twin }}$ & $h_{s l, 0}$ & $h_{t w, 0}$ & $\lambda$ \\
\hline 78 & 15 & 110 & 250 & 50 & 200 & 500 & 0.5 \\
\hline 298 & 15 & 75 & 170 & 50 & 80 & 500 & 0.5 \\
\hline 473 & 15 & 65 & 160 & 40 & 50 & 500 & 0.6 \\
\hline
\end{tabular}

Material parameters used in the constitute model for AZ31B at different temperatures. $S_{s l} \sim \infty$ and $S_{t w} \sim \infty$, or $a_{s l} \sim 0 a_{t w} \sim 0$ are used for linear hardening. Those numbers are obtained by fitting the simulation results to stress-strain curves from experiments (for both tensile and compressive curves in the $L$ - and $R$ samples). 
a relatively high slip resistance in basal slip systems so that our numerical predictions can match well with experimental stress-strain behaviors and texture evolutions. It seems reasonable given the rather fine grain structures in our samples (see Fig. 1c), and this number is consistent with the reported values from several groups (Agnew et al., 2003, 2006; Barnett et al., 2006; Fernandez et al., 2011; Hutchinson and Barnett, 2010; Muranskya et al., 2008).

- Hardening parameters for slip and twinning: In the power-law hardening, we have three parameters $\left\{h_{s l, 0}, S_{s l}, a_{s l}\right\}$ for slip induced hardening, and three parameters $\left\{h_{t w, 0}, S_{t w}, a_{t w}\right\}$ for twin induced hardening. Linear hardening coefficient $\left(h_{s l, 0}\right.$ and $h_{t w, 0}$ ) value for slip and twinning respectively are shown in Table 2.

\subsection{Simulation result}

The equivalent plastic strain for one type of slip systems can be calculated as follows:

$$
\dot{\bar{\gamma}}_{s l}=\sqrt{2 / 3\left(\sum_{i} \dot{\gamma}_{s l}^{i} S_{0}^{i}\right):\left(\sum_{i} \dot{\gamma}_{s l}^{i} S_{0}^{i}\right)}, \quad \Delta \gamma_{s l}=\int \dot{\bar{\gamma}}_{s l} d t
$$

where $i$ covers all the slip systems in that type. Similarly, the equivalent plastic strain for a twinning system is defined as:

$$
\dot{\bar{\gamma}}_{t w}=\sqrt{2 / 3\left(\sum_{\alpha} \dot{\gamma}_{t w}^{\alpha} S_{0}^{\alpha}\right):\left(\sum_{\alpha} \dot{\gamma}_{t w}^{\alpha} S_{0}^{\alpha}\right)}, \quad \Delta \gamma_{t w}=\int \dot{\bar{\gamma}}_{t w} d t
$$

with $\alpha$ including all the twinning systems in that type. The averaged principal stress in grain $N$ is calculated as:

$$
\bar{\sigma}_{33}^{N}=\frac{1}{V_{N}} \sum_{j} V_{j} \sigma_{j}
$$

where $j$ covers all the elements in the $N$-th grain, and $V_{j}$ the volume of the $j$-th element and $V_{N}$ is the volume of the grain

The fitted stress-strain curve, corresponding strain fraction curves, and averaged principal stress for 300 crystals are shown in Fig. 5. As seen in the top part of Fig. 5a-d, the parameters given in Table 2 can capture the mechanical response of AZ31B very well. From the strain fraction versus strain curves in the middle of Fig. 5a-d, we find that deformation in the $R$ direction is accommodated by all four types of mechanisms including dislocation slips and deformation twinning, which could account for the nearly symmetrical yielding behavior while compression and tension. For deformation at different temperatures, the slip and twin activities are quite similar. It may be due to the fact that the same slip and twin systems are activated in all our simulations. In addition, high level stress fluctuation at the grain level is seen in all simulations.

Fig. 6 shows the contour plots of the maximum principal stress and equivalent plastic strain (PEEQ) for $L$-sample at $298 \mathrm{~K}$ and at a tensile strain of 0.17 , where we see significant stress and deformation inhomogeneity at the grain level. Such high level stress and plastic deformation fluctuations may be the causes to trigger excessive grain boundary deformation, which results in premature failure and low ductility in magnesium alloys.

Fig. 7 gives the pole figures of deformed $L$-samples from both experiments and those via simulations. It can be seen that the simulated results are in good accordance with the corresponding experimental results. Based on the $\{0001\}$ pole figures in Fig. 8, we determine quantitatively the twin volume fraction from both experiments and simulations. As the $\left\{\begin{array}{lll}0 & 1 & 1\end{array}\right\}\langle\overline{1} 011\rangle$ extension twin produces a $86^{\circ}$ reorientation to the basal plane, we calculate the extension twin volume fraction from the density change in basal pole figures by integrating over the tilting angle between $0^{\circ}$ and $45^{\circ}$ (Li et al., 2012 ; Ma et al., 2012). The twin volume fractions from both experiments and simulations at $298 \mathrm{~K}$ are given in Table 3 . When the twin volume is relatively low, our simulation matches well with experimental results. For large twin volume fraction, however, we see apparent difference. It could be caused by the occurrence of secondary twins when primary twin volume fraction is greater than $\sim 0.3$. The limited number of representative orientations used in our simulations could make a difference as well.

In addition to match well with the stress-strain responses and the texture evolution, our numerical simulations also capture the macrostructure shape evolution due to plastic deformation in AZ31B, as illustrated in Fig. 8. Fig. 8a gives the crosssection (parallel to plane B) of a $R$-sample after 0.17 compressive strain at $298 \mathrm{~K}$. The cross section has an eccentricity of 0.43 illustrating clearly the anisotropic nature of deformation in AZ31B. Corresponding simulation with the same loading conditions is shown in Fig. 8 b, which has an eccentricity of 0.35 , with its minor axis of the ellipse parallel to the $L$ direction. It is noted that such anistropic macroscopic shape change is not seen in $L$-samples. In order to capture the macroscopic shape

Table 3

Comparison of extension twin volume fraction at room temperature from both experiment and simulation. The extension twin volume fraction is calculated from basal pole figures with tilting angle between $0^{\circ}$ and $45^{\circ}$.

\begin{tabular}{lllll}
\hline & $L$-ten. & $L$-com. & $R$-ten. & $R$-com. \\
\hline Exp. & 0.06 & 0.73 & 0.43 & 0.18 \\
FEM & 0.00 & 0.96 & 0.76 & 0.19 \\
\hline
\end{tabular}




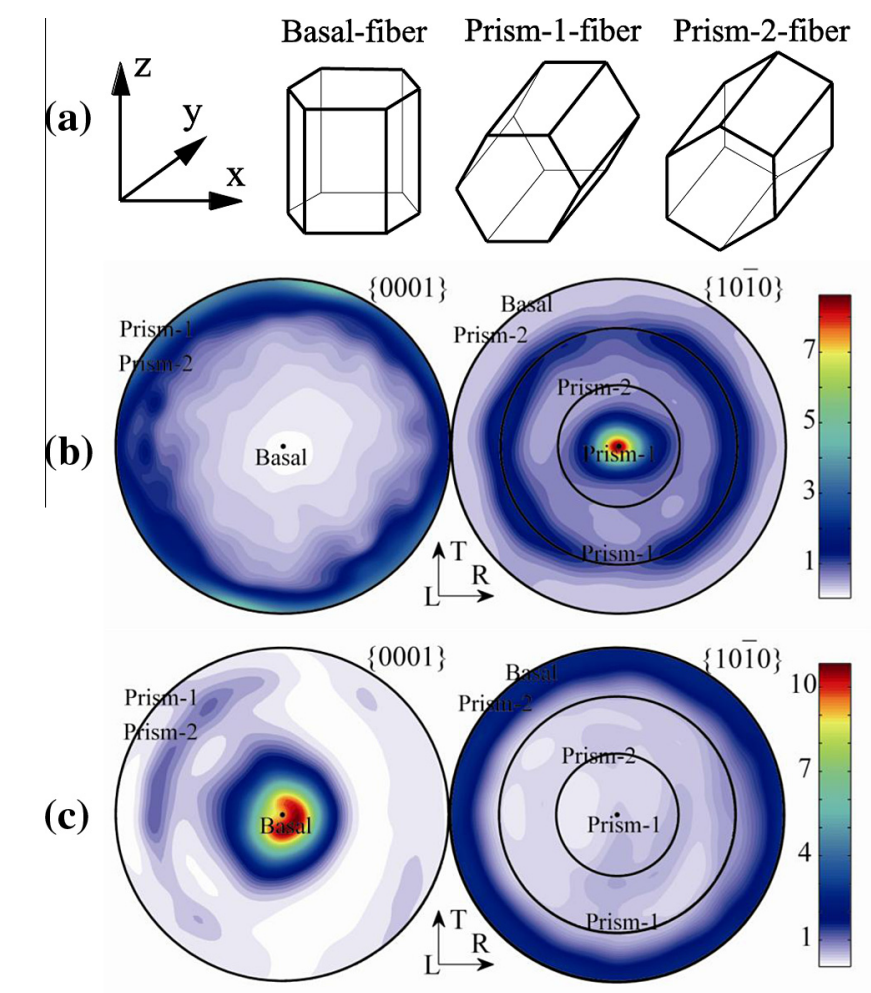

Fig. 9. Illustration of three representative fibers and corresponding pole figures. (a) Three typical fibers in magnesium rod. The combined pole figures for 'Basal-fiber'/'Prism-1-fiber'/'Prism-2-fiber' and experimental results after tension and compression tests are shown in (b) and (c), respectively.

change, we need a sufficiently large number of different orientations in the cross-section of a sample. Limited by computation expenses, we adopt cubic grains with each element representing one orientation.

\section{Numerical tests for three fibers in magnesium rod}

In the previous section, we have shown intensive application of the numerical results to polycrystalline magnesium, which agree well with experimental observations. Now we aim to shed light on rather simple systems so that a better
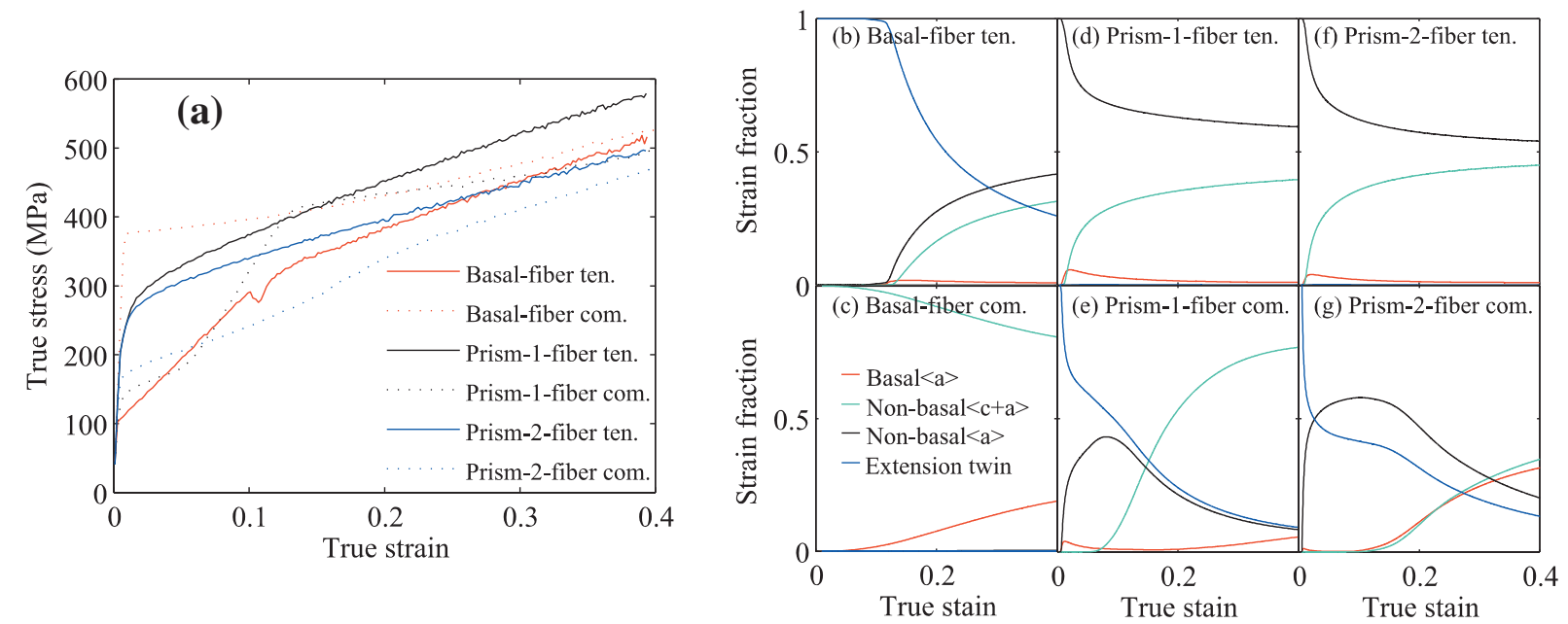

Fig. 10. Deformation behavior of the three types of fibers shown in Fig. 9a. (a) The stress-strain responses. Strain fractions as a function of applied strains for (b) 'Basal-fiber' in tension, (c) 'Basal-fiber' in compression, (d) 'Prism-1-fiber' in tension, (e) 'Prism-1-fiber' in compression, (f) 'Prism-2-fiber' in tension, and $(\mathrm{g})$ 'Prism-2-fiber' in compression. 
physical picture for the activation of plastic deformation mechanisms can be obtained. Based on the experimental observation on pole figures, we find three representative fibers in the given Cartesian coordinate system, which we label as 'Basalfiber', 'Prism-1-fiber' and 'Prism-2-fiber'(as shown in Fig. 9a), Here 'Basal-fiber', 'Prism-1-fiber' and 'Prism-2-fiber', in turn, are the set of single crystals with z-axis perpendicular to crystal's basal plane $\{0001\}$, type 1 prismatic plane $\{10 \overline{1} 0\}$, and type 2 prismatic plane $\{10 \overline{2} 0\}$ respectively. Each set of fiber represents a cluster of crystals which share one common axis but the other two axes of the crystals are randomly distributed. Those typical fiber textures induced by customized manufacture process such as rolling texture and extrude texture have been reported frequently (Bohlen et al., 2005; Kelley and Hosford, 1968; Styczynski et al., 2004). Note that we have assumed that such crystals have a uniform distribution in the $x-y$ plane here. For convenience, we superpose the pole figures of those fibers to the pole figures in Fig. 7a and c. We see that

Table 4

Mechanical properties and the crystal orientations for 'Basal-fiber'/'Prism-1-fiber'/'Prism-2-fiber' at room temperature, while 'First/S' refers to the first activated slip or twinning system, 'Status (40\%)'represents the main crystal orientation at the true strain of 0.4 .

\begin{tabular}{|c|c|c|c|c|c|c|}
\hline \multirow{2}{*}{$\begin{array}{l}\text { Fiber type } \\
\text { Model }\end{array}$} & \multicolumn{2}{|c|}{ Basal-fiber } & \multicolumn{2}{|c|}{ Prism-1-fiber } & \multicolumn{2}{|c|}{ Prism-2-fiber } \\
\hline & $T$ & $C$ & $T$ & $C$ & $T$ & $C$ \\
\hline $0.2 \% \sigma_{y} / \mathrm{MPa}$ & 105 & 380 & 225 & 125 & 223 & 163 \\
\hline First/S & $T$-twin & $\begin{array}{l}\text { Non-basal } \\
\langle c+a\rangle \text { slip }\end{array}$ & $\begin{array}{l}\text { Non-basal } \\
\langle\text { a }\rangle \text { slip }\end{array}$ & $T$-twin & $\begin{array}{l}\text { Non-basal } \\
\langle a\rangle \text { slip }\end{array}$ & $T$-twin \\
\hline$\sigma_{u t s} / \mathrm{MPa}$ & 340 & 985 & 390 & 909 & 334 & 893 \\
\hline Status (40\%) & B & A & B & A & C & A \\
\hline
\end{tabular}

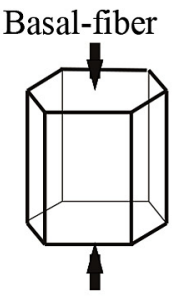

(a)

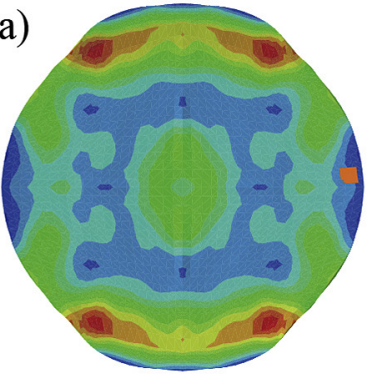

(c)
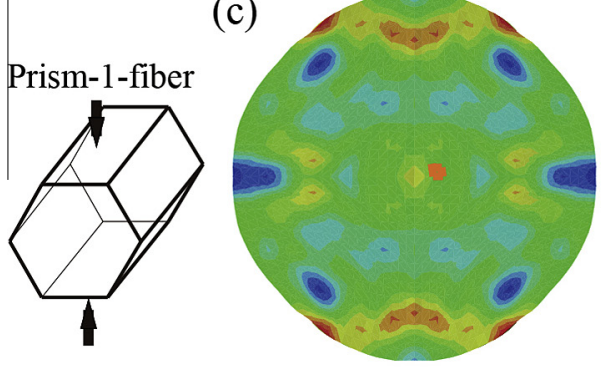

(e)

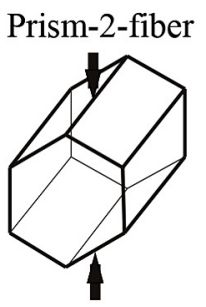

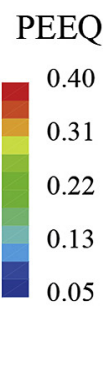

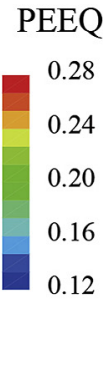

PEEQ

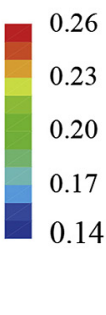

(b)

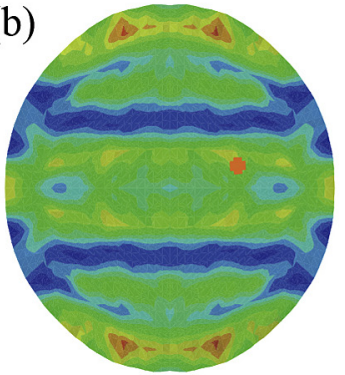

PEEQ

(d)

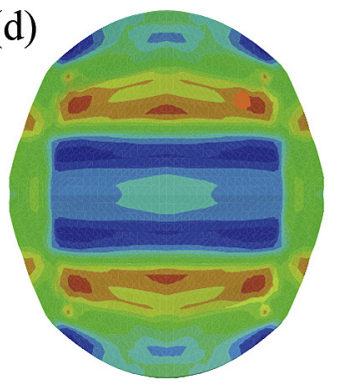

PEEQ

(f)

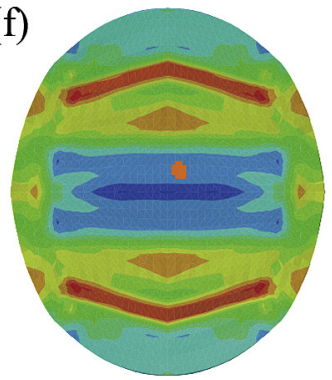

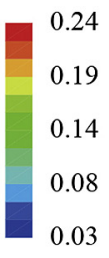

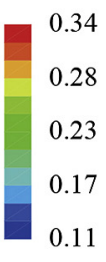

PEEQ

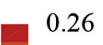

0.20

0.14

0.08

0.02

Fig. 11. Macroscopic shape change and deformation contour from simulations on samples with 'Basal-fiber'/'Prism-1-fiber'/'Prism-2-fiber' at the true compressive strain of 0.17 . Deformation is applied along the fiber axis or along the direction perpendicular to the fiber axis. (a) Along 'Basal-fiber' and (b) perpendicular to 'Basal-fiber'; the latter shows an eccentricity of 0.51. (c) along 'Prism-1-fiber' and (d) perpendicular to 'Prism-1-fiber'; the latter shows an eccentricity of 0.55 . (e) Along 'Prism-2-fiber' and (f) perpendicular to 'Prism-2-fiber', the latter has an eccentricity of 0.64. 
'Basal-fiber' is the dominant crystal orientation after compressive deformation (Fig. 9c), while 'Prism-1-fiber' is the dominant crystal orientation after tensile deformation (Fig. 9b).

In order to clarify the contribution of 'Basal-fiber'/'Prism-1-fiber'/'Prism-2-fiber' to the stress-strain curves and shape change during the deformation in polycrystalline magnesium, we perform simulation using the material parameters for magnesium at room temperature, with loading direction parallel to fiber axis ( $z$-axis as illustrated in Fig. 9a). Fig. 10 shows the results from our numerical tests, including the stress-strain behavior of the three types of fibers (Fig. 10a) and corresponding evolution of strain fractions during deformation (Fig. 10b-g). The summarized information is listed in Table 4. It can be concluded that the presence of extension twin has a great influence on the strain hardening. The asymmetrical stress-strain response is due primarily to the strong anisotropic resistance to slip and deformation twinning. Deformation in $L$-sample while compression can be approximated to the simple case of compressing 'Prism-1-fiber' in $z$-axis, while the response in $R$-sample while compression resembles applying compression to 'Prism-1-fiber' in $x$-axis. In addition, by examining the macroscopic shape change from simulations on fibers loading along different directions at the true strain of 0.17 (Fig. 11), we find that fiber 'Prism-1-fiber' subjected to compression along $x$-axis gives rise to an elliptical cross-section with the eccentricity of 0.55 (Fig. 11d). In contrast, samples with texture fibers 'Basal-fiber'/'Prism-1-fiber'/'Prism-2-fiber' subjected to compression along $z$-axis do not show any elliptical cross-section. Therefore, it is safe to conclude that the elliptical shape we observed from experiments (Fig. 8a) is primarily originated from basal slips in type 'Prism-1-fiber' in AZ31B while compressing applied in the $R$ direction. By looking at the yield stress in different fiber samples given in Table 4, we see that the ultimate yield stress could reach $380 \mathrm{MPa}$ in compression along the 'Basal-fiber'. This value is in good accordance with the maximum yield stress in current experiment (Kim et al., 2009).

\section{Conclusion}

Systematic experimental for the mechanical properties of as-drawn AZ31B at temperatures between 78 and $473 \mathrm{~K}$ were performed. We then employ the crystal plasticity constitutive model developed by Staroselsky and Anand $(1998,2003)$, which accounts for both dislocation slip and deformation twinning in polycrystalline magnesium. By adjusting the material parameters so that the computational results can match the stress-strain responses and texture evolution in AZ31B deforming at different temperatures and subjected to different boundary value problems, we obtain the dependence of CRSS on temperature, as well as the fractional plastic strains contributed by individual slip/twinning systems at different temperatures. The major results of this investigation are follows.

1. The grain boundary and grain size effect is not regarded as the primary mechanism accounting for the strong asymmetrical stress-strain behavior before intermediate strain since samples loading along the axial directions show strong asymmetry but those loaded along the radial direction have weak asymmetry in the stress-strain response. It hence suggests the possibility to eliminate the tension-compression asymmetry in magnesium alloys by adopting suitable manufacturing processes. For example, lowering extrusion ration or adapting different types of rolling procedure were proposed (Hirsch and Al-Samman, 2013; Kim et al., 2009; Shahzad and Wagner, 2009).

2. The resistances in non-basal slip systems show clear temperature-dependence, with higher resistances at lower temperatures. However, the resistances for basal slip and extension twin are not as sensitive as those in non-basal slip systems. This conclusion is limited in the temperature region where dislocation gliding and twinning induced plasticity is dominant. At temperature above $473 \mathrm{~K}$, more complicated deformation mechanism such as grain boundary activities and dislocation climbing occur (Koike et al., 2003b).

3. Significant stress and deformation inhomogeneity at the grain level is observed. Such high level stress and plastic deformation fluctuations may trigger excessive grain boundary deformation, which results in premature failure and low ductility in magnesium alloys.

It is worth pointing out that plastic deformation by grain boundary sliding may also be active in AZ31B, especially at high temperature (Hauser et al., 1955; Koike et al., 2003b; Staroselsky and Anand, 2003). This effect is not considered in our finiteelement simulations in the present study.

\section{Acknowledgments}

Y.W. acknowledges support from the Chinese Academy of Sciences (KJCX2-EW-L03), MOST 973 of China (Nos. 2012CB937500, 2011CB711103), and NSFC (11021262). We are very grateful to Professor Lallit Anand at MIT for fruitful discussions.

\section{References}

Agnew, S.R., Brown, D.W., Tome, C.N., 2006. Validating a polycrystal model for the elastoplastic response of magnesium alloy AZ31 using in situ neutron diffraction. Acta Mater. 54, 4841-4852.

Agnew, S.R., Duygulu, O., 2005. Plastic anisotropy and the role of non-basal slip in magnesium alloy AZ31B. Int. J. Plast. 21, 1161-1193.

Agnew, S.R., Tome, C.N., Brown, D.W., Holden, T.M., Vogel, S.C., 2003. Study of slip mechanisms in a magnesium alloy by neutron diffraction and modeling. Scr. Mater. 48, 1003-1008. 
Alves, H., Koster, U., Aghion, E., Eliezer, D., 2001. Environmental behavior of magnesium and magnesium alloys. Mater. Technol. 16, $110-126$.

Ando, S., Tonda, H., 2000. Non-Basal slip in magnesium-lithium alloy single crystals. Mater. Trans. JIM 41, $1188-1191$.

Bachmann, F., Hielscher, R., Schaeben, H., 2010. Texture analysis with MTEX - free and open source software toolbox. In: Klein, H., Schwarzer, R.A. (Eds.), Texture and Anisotropy of Polycrystals Iii, pp. 63-68.

Barnett, M.R., 2007. Twinning and the ductility of magnesium alloys Part II. “Contraction” twins. Mat. Sci. Eng. a-Struct. Mater. Prop. Microstruct. Process. $464,8-16$.

Barnett, M.R., Ghaderi, A., Sabirov, I., Hutchinson, B., 2009. Role of grain boundary sliding in the anisotropy of magnesium alloys. Scr. Mater. 61, 277-280.

Barnett, M.R., Keshavarz, Z., Beer, A.G., Atwell, D., 2004. Influence of grain size on the compressive deformation of wrought Mg-3Al-1Zn. Acta Mater. 52, 5093-5103.

Barnett, M.R., Keshavarz, Z., Ma, X., 2006. A semianalytical Sachs model for the flow stress of a magnesium alloy. Metall. Mater. Trans. a-Phys. Metall. Mater. Sci. 37A, 2283-2293.

Beyerlein, I.J., McCabe, R.J., Tome, C.N., 2011. Effect of microstructure on the nucleation of deformation twins in polycrystalline high-purity magnesium: a multi-scale modeling study. J. Mech. Phys. Solids 59, 988-1003.

Bohlen, J., Yi, S.B., Swiostek, J., Letzig, D., Brokmeier, H.G., Kainer, K.U., 2005. Microstructure and texture development during hydrostatic extrusion of magnesium alloy AZ31. Scr. Mater. 53, 259-264.

Cazacu, O., Plunkett, B., Barlat, F., 2006. Orthotropic yield criterion for hexagonal closed packed metals. Int. J. Plast. 22, 1171-1194.

Chino, Y., Kimura, K., Hakamada, M., Mabuchi, M., 2008. Mechanical anisotropy due to twinning in an extruded AZ31 Mg alloy. Mater. Sci. Eng. A-Struct. Mater. Prop. Microstruct. Process. 485, 311-317.

Choi, S.H., Kim, D.H., Park, S.S., You, B.S., 2010. Simulation of stress concentration in Mg alloys using the crystal plasticity finite element method. Acta Mater. $58,320-329$.

Cipoletti, D.E., Bower, A.F., Krajewski, P.E., 2011. A microstructure-based model of the deformation mechanisms and flow stress during elevatedtemperature straining of a magnesium alloy. Scr. Mater. 64, 931-934.

Eros, S., Smith, C.S., 1961. Low-temperature elastic constants of magnesium alloys. Acta Metall. 9, 14-22.

Fernandez, A., Perez Prado, M.T., Wei, Y., Jerusalem, A., 2011. Continuum modeling of the response of a Mg alloy AZ31 rolled sheet during uniaxial deformation. Int. J. Plast. 27, 1739-1757.

Gottstein, G., 2004. Physical Foundation of Materials Science. Springer, Berlin.

Graff, S., Brocks, W., Steglich, D., 2007. Yielding of magnesium: from single crystal to polycrystalline aggregates. Int. J. Plast. 23, 1957-1978.

Haferkamp, H., Boehm, R., Holzkamp, U., Jaschik, C., Kaese, V., Niemeyer, M., 2001. Alloy development, processing and applications in magnesium lithium alloys. Mater. Trans. 42, 1160-1166.

Hama, T., Takuda, H., 2011. Crystal-plasticity finite-element analysis of inelastic behavior during unloading in a magnesium alloy sheet. Int. J. Plast. 27, $1072-1092$.

Hauser, F.E., Starr, C.D., Tietz, L., Dorn, J.E., 1955. Deformation mechanisms in polycrystalline aggregates of magnesium. Trans. ASM 47, $102-134$.

Hearmon, R.F.S., 1946. The elastic constants of anisotropic materials. Rev. Mod. Phys. 18, 409-440.

Hielscher, R., Schaeben, H., 2008. A novel pole figure inversion method: specification of the MTEX algorithm. J. Appl. Crystallogr. 41, $1024-1037$.

Hirsch, J., Al-Samman, T., 2013. Superior light metals by texture engineering: optimized aluminum and magnesium alloys for automotive applications. Acta Mater. 61, 818-843.

Hutchinson, W.B., Barnett, M.R., 2010. Effective values of critical resolved shear stress for slip in polycrystalline magnesium and other hcp metals. Scr. Mater. 63, 737-740.

Kalidindi, S.R., 1998. Modeling the strain hardening response of low SFE FCC alloys. Int. J. Plast. 14, 1265-1277.

Kalidindi, S.R., Bronkhorst, C.A., Anand, L., 1992. Crystallographic texture evolution in bulk deformation processing of FCC metals. J. Mech. Phys. Solids 40, 537-569.

Kelley, E.W., Hosford, W.F., 1968. Plane-strain compression of magnesium and magnesium alloy crystals. Trans. Metall. Soc. AIME 242, 5-13.

Kelly, A., Knowles, K.M., 2012. Twinning, Crystallography and Crystal Defects. John Wiley \& Sons Ltd., New York, pp. $335-361$.

Khan, A.S., Lopez-Pamies, O., Kazmi, R., 2006. Thermo-mechanical large deformation response and constitutive modeling of viscoelastic polymers over a wide range of strain rates and temperatures. Int. J. Plast. 22, 581-601.

Kim, H.K., 2009. The grain size dependence of flow stress in an ECAPed AZ31 Mg alloy with a constant texture. Mater. Sci. Eng. a-Struct. Mater. Prop. Microstruct. Process. 515, 66-70.

Kim, W.J., Jeong, H.G., Jeong, H.T., 2009. Achieving high strength and high ductility in magnesium alloys using severe plastic deformation combined with low-temperature aging. Scr. Mater. 61, 1040-1043.

Kim, W.J., Kim, H.K., Kim, W.Y., Han, S.W., 2008. Temperature and strain rate effect incorporated failure criteria for sheet forming, of magnesium alloys. Mater. Sci. Eng. a-Struct. Mater. Prop. Microstruct. Process. 488, 468-474.

Kochmann, D.M., Le, K.C., 2009. A continuum model for initiation and evolution of deformation twinning. J. Mech. Phys. Solids 57, 987-1002.

Koike, J., Kobayashi, T., Mukai, T., Watanabe, H., Suzuki, M., Maruyama, K., Higashi, K., 2003a. The activity of non-basal slip systems and dynamic recovery at room temperature in fine-grained AZ31B magnesium alloys. Acta Mater. 51, 2055-2065.

Koike, J., Ohyama, R., Kobayashi, T., Suzuki, M., Maruyama, K., 2003b. Grain-boundary sliding in AZ31 magnesium alloys at room temperature to 523 K. Mater. Trans. 44, 445-451.

Kulekci, M.K., 2008. Magnesium and its alloys applications in automotive industry. Int. J. Adv. Manuf. Technol. 39, 851-865.

Lévesque, J., Inal, K., Neale, K.W., Mishra, R.K., 2010. Numerical modeling of formability of extruded magnesium alloy tubes. Int. J. Plast. 26, 65-83.

Lee, M.-G., Wagoner, R.H., Lee, J.K., Chung, K., Kim, H.Y., 2008a. Constitutive modeling for anisotropic/asymmetric hardening behavior of magnesium alloy sheets. Int. J. Plast. 24, 545-582.

Lee, Y.S., Kwon, Y.N., Kang, S.H., Kim, S.W., Lee, J.H., 2008b. Forming limit of AZ31 alloy sheet and strain rate on warm sheet metal forming. J. Mater. Process. Technol. 201, 431-435.

Lee, M.G., Kim, S.J., Wagoner, R.H., Chung, K., Kim, H.Y., 2009. Constitutive modeling for anisotropic/asymmetric hardening behavior of magnesium alloy sheets: application to sheet springback. Int. J. Plast. 25, 70-104.

Leffers, T., 2001. A model for rolling deformation with grain subdivision. Part I: the initial stage. Int. J. Plast. 17, 469-489.

Li, B., Joshi, S.P., Almagri, O., Ma, Q., Ramesh, K.T., Mukai, T., 2012. Rate-dependent hardening due to twinning in an ultrafine-grained magnesium alloy. Acta Mater. 60, 1818-1826.

Li, M., Lou, X.Y., Kim, J.H., Wagoner, R.H., 2010. An efficient constitutive model for room-temperature, low-rate plasticity of annealed Mg AZ31B sheet. Int. J. Plast. 26, 820-858.

Liu, Y., Wang, W., Xie, J., Sun, S., Wang, L., Qian, Y., Meng, Y., Wei, Y., 2012. Microstructure and mechanical properties of aluminum 5083 weldments by gas tungsten arc and gas metal arc welding. Mater. Sci. Eng. A 549, 7-13.

Luo, A.A., 2002. Magnesium: current and potential automotive applications. JOM 54, 42-48.

Ma, Q., El Kadiri, H., Oppedal, A.L., Baird, J.C., Li, B., Horstemeyer, M.F., Vogel, S.C., 2012. Twinning effects in a rod-textured AM30 Magnesium alloy. Int. J. Plast. 29, 60-76.

Mabuchi, M., Chino, Y., Iwasaki, H., 2003. Influence of grain size on elongation at elevated temperatures in AZ31 Mg alloy. Mater. Trans. 44, 490-495.

Mayama, T., Noda, M., Chiba, R., Kuroda, M., 2011. Crystal plasticity analysis of texture development in magnesium alloy during extrusion. Int. J. Plast. 27, $1916-1935$.

Mo, J.P., Cheng, X.N., Ru, J.M., Xu, X.J., 2011. Effect of initial microstructure on deformation mechanisms of AZ31 magnesium alloy. In: Han, Y.F., Pan, F., Tang, J.M., Zhou, C.G. (Eds.), Advanced Structural Materials. Trans Tech Publications Ltd, Stafa-Zurich, pp. 68-73. 
Mu, S., Al-Samman, T., Mohles, V., Gottstein, G., 2010. Implementation of mechanical twinning in a grain interaction model: application to magnesium alloys. Adv. Eng. Mater. 12, 1008-1014.

Mu, S., Al-Samman, T., Mohles, V., Gottstein, G., 2011. Cluster type grain interaction model including twinning for texture prediction: application to magnesium alloys. Acta Mater. 59, 6938-6948.

Muranskya, O., Carr, D.G., Barnett, M.R., Oliver, E.C., Sittner, P., 2008. Investigation of deformation mechanisms involved in the plasticity of AZ31 Mg alloy: In situ neutron diffraction and EPSC modelling. Mater. Sci. Eng. a-Struct. Mater. Prop. Microstruct. Process. 496, $14-24$.

Myagchilov, S., Dawson, P.R., 1999. Evolution of texture in aggregates of crystals exhibiting both slip and twinning. Modell. Simul. Mater. Sci. Eng. 7, 9751004.

Pitteri, M., 1985. On v+1-lattices. J. Elast. 15, 3-25.

Pitteri, M., 1986. On type-2 twins in crystals. Int. J. Plast. 2, 99-106.

Proust, G., Tome, C.N., Jain, A., Agnew, S.R., 2009. Modeling the effect of twinning and detwinning during strain-path changes of magnesium alloy AZ31. Int. J. Plast. 25, 861-880.

Shahzad, M., Wagner, L., 2009. Influence of extrusion parameters on microstructure and texture developments, and their effects on mechanical properties of the magnesium alloy AZ80. Mater. Sci. Eng. A 506, 141-147.

Simmons, G., Wang, H., 1971. Single Crystal Elastic Constants and Calculated Aggregate Properties. The M.I.T Press, Cambridge.

Staroselsky, A., Anand, L., 1998. Inelastic deformation of polycrystalline face centered cubic materials by slip and twinning. J. Mech. Phys. Solids 46, 671696.

Staroselsky, A., Anand, L., 2003. A constitutive model for hcp materials deforming by slip and twinning: application to magnesium alloy AZ31B. Int. J. Plast. 19, 1843-1864.

Styczynski, A., Hartig, C., Bohlen, J., Letzig, D., 2004. Cold rolling textures in AZ31 wrought magnesium alloy. Scr. Mater. $50,943-947$.

Taylor, G.I., 1938. Plastic strain in metals. J. Inst. Metals 62, 307-324.

Tomé, C.N., Lebensohn, R.A., Kocks, U.F., 1991. A model for texture development dominated by deformation twinning: application to zirconium alloys. Acta Metall. Mater. 39, 2667-2680.

Van Houtte, P., 1978. Simulation of the rolling and shear texture of brass by the Taylor theory adapted for mechanical twinning. Acta Metall. 26, 591-604.

Walde, T., Riedel, H., 2007a. Modeling texture evolution during hot rolling of magnesium alloy AZ31. Mater. Sci. Eng. a-Struct. Mater. Prop. Microstruct. Process. 443, 277-284.

Walde, T., Riedel, H., 2007b. Simulation of earing during deep drawing of magnesium alloy AZ31. Acta Mater. 55, 867-874.

Wang, B., Xin, R., Huang, G., Liu, Q., 2012. Effect of crystal orientation on the mechanical properties and strain hardening behavior of magnesium alloy AZ31 during uniaxial compression. Mater. Sci. Eng. A 534, 588-593.

Wang, H., Raeisinia, B., Wu, P.D., Agnew, S.R., Tomé, C.N., 2010a. Evaluation of self-consistent polycrystal plasticity models for magnesium alloy AZ31B sheet. Int. J. Solids Struct. 47, 2905-2917.

Wang, H., Wu, P.D., Tome, C.N., Huang, Y., 2010b. A finite strain elastic-viscoplastic self-consistent model for polycrystalline materials. J. Mech. Phys. Solids $58,594-612$

Wei, Y., Anand, L., 2007. A constitutive model for powder-processed nanocrystalline metals. Acta Mater. 55, 921-931.

Wu, B.L., Zhang, Y.D., Wan, G., Humbert, M., Wagner, F., Esling, C., 2012. Primary twinning selection with respect to orientation of deformed grains in ultrarapidly compressed AZ31 alloy. Mater. Sci. Eng. A 541, 120-127.

Yang, P., Yu, Y., Chen, L., Mao, W., 2004. Experimental determination and theoretical prediction of twin orientations in magnesium alloy AZ31. Scr. Mater. 50, $1163-1168$.

Yang, Q., Ghosh, A.K., 2006. Deformation behavior of ultrafine-grain (UFG) AZ31B Mg alloy at room temperature. Acta Mater. 54, 5159-5170.

Yuan, W., Mishra, R.S., Carlson, B., Mishra, R.K., Verma, R., Kubic, R., 2011. Effect of texture on the mechanical behavior of ultrafine grained magnesium alloy. Scr. Mater. 64, 580-583. 